CONTEXT

MATTERS:

LUCK AND THE

PARADOX OF SKILL

\section{RYAN MINDELL}

Ryan Mindell is the lottery operations director of the Texas Lottery Commission and is also a licensed attorney. This article was written in his personal capacity. The views expressed are solely his own and are not presented as or necessarily representative of the views of the Texas Lottery Commission. His e-mail address is ryanmindell@gmail.com.

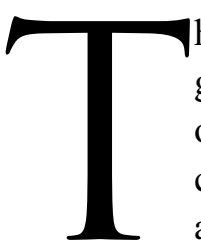

The law looks at games and decides: the game is either one of luck, one of skill, or a mix of both. While the trickiest decisions involve the games that mix luck and skill, the entire analysis is premised on the questionable idea that some games are pure games of skill. That view may be altogether incorrect.

Generally speaking, state law defines gambling as requiring consideration, prize, and chance. In determining if a game involves chance, laws break down into three main categories. First, the dominant element test, which looks to whether chance predominates over skill, is the law in most states. ${ }^{1}$ Second, the material element test, which looks to whether chance is present in any material degree, is the law in some states. ${ }^{2}$ Third, the any chance test, which looks to whether any chance is present, is the law in a few states. ${ }^{3}$ Courts analyze games based on the legally applicable standard by determining the amount of chance in a game as an absolute matter. In other words, courts (and others interpreting the law, such as attorneys general or district attorneys) assess the amount of chance in a game without regard to any contextual factors. Based on this determination, the game is identified as having a dominant element of chance, a material element of chance, or any element of chance, as appropriate for that state's standard.

To determine whether a game involves chance, we need to define chance. One way to think of chance is whether another outcome was reasonably possible. The entire premise of chance is that it is outside of one's control. ${ }^{4}$ Skill, on the other hand, is what one can control, either through practice or natural talent. ${ }^{5}$ The legal analysis balances the two against each other: games are defined by a combination of luck and skill. Therefore, the outcomes in any contest must naturally be decided by a simple equation - it will be equal to the difference in the skill of the participants (what they can control) plus the difference in their luck (what they cannot control). In a lottery, there is no skill variance. No participant has any natural or learned ability to select the correct numbers, and so the outcome is completely dependent on the variance in chance between the participants. In chess, there is very little variance in chance, so the outcome is determined mostly by the variance in skill.

However, this leads to what investment strategist Michael Mauboussin has termed the "paradox of skill." As the difference in skill lessens between competing participants, the outcome of a contest is necessarily determined more by the difference in chance between them. ${ }^{7}$ If two participants are equally skilled, the outcome will be wholly determined by factors outside their skill, even in a game
Keywords: chance, skill, context, luck, daily fantasy

DOI: $10.1089 / \mathrm{glr} 2.2018 .2253$ C 2018 Mary Ann Liebert, Inc.

${ }^{1}$ See, e.g., O’Brien v. Scott, 89 A.2d 280, 283 (N.J. Super. Ct. Ch. Div. 1952); Commonwealth v. Lake, 57 N.E.2d 923, 925 (Mass. 1944); Three Kings Holdings, L.L.C. v. Six, 255 P.3d 1218, 1223 (Kan. Ct. App. 2011); In re Allen, 377 P.2d. 280, 281 (Cal. 1962).

${ }^{2}$ See, e.g., Gilman v. Martin, 662 P.2d 120, 124 n.1 (Alaska 1983); Hawaii v. Sur, 39 Haw. 332, 337-39 (1952); Thole v. Westfall, 682 S.W.2d 33, 36-37 (Mo. Ct. App. 1984); State v. Koo, 647 P.2d 889, 891-92 (Okla. Crim. App. 1982).

${ }^{3}$ See, e.g., Parker-Gordon Importing Co. v. Benakis, 238 N.W. 611, 613 (Iowa 1931); State v. Gambling Device, 859 S.W.2d 519, 523 (Tex. App.-Houston [1st Dist.] 1993).
${ }^{4}$ See, e.g., chance, Black's Law Dictionary (10th ed. 2014) ("the unforeseen, uncontrollable, or unintended consequences of an act"); chance, MERriamWeBSTER.COM DictionaRY (https://www.merriam-webster.com/dictionary/chance) ("something that happens unpredictably without discernible human intention or observable cause").

${ }^{5}$ See, e.g., skill, BLACK's LAW DictionaRy (10th ed. 2014) (“Ability; proficiency”); skill, Merriam-Webster.com Dictionary (https://www.merriam-webster.com/ dictionary/skill) ("a learned power of doing something competently : a developed aptitude or ability").

${ }^{6}$ Michael J. Mauboussin, The Success Equation 53 (2012).

${ }^{7}$ Id. at 78 . 
like chess. For instance, the random factor of who went first or whether one participant got more sleep the night before will affect the result. Even without any systemic elements of chance present, a single game of chess between exactly equal skilled participants will therefore be determined by chance. The context of the game matters. A game of poker between an expert and a player who knows nothing about the game is hardly a game of chance. The expert will win the clear majority of the time because the difference of skill is so large.

For jurisdictions that seek to analyze whether skill or luck is dominant, the context of the participants can help guide the analysis. For instance, in tennis, even a small advantage in skill on each individual point can lead to a large advantage across a match. A 53 percent chance of winning each point can lead to an 85 percent chance of winning a match. ${ }^{8}$ The range of skill for luck to become the dominant factor is relatively small. In the chess example, luck only becomes the dominant factor in a very narrow range of skill - when the skill of the participants is very close. But for jurisdictions that seek to analyze whether any luck is present in games, the range of skill should not matter; some games of tennis and chess will still be determined by luck. While games can be purely decided by luck, no game is determined solely on the basis of skill.

Of course, skill itself is often changing and rarely measurable. But as courts and policymakers seek to place games themselves on a continuum, the contextual differences of skill and chance are ignored. Take the relatively recent explosion of attention to daily fantasy games, especially by legislatures, attorneys general, and courts across the country. One overriding question appeared - is daily fantasy a

${ }^{8}$ Ian Stewart, Game, Set and Math: Enigmas and Conundrums 15-30 (1989).

${ }^{9}$ Davey Alba, Does Winning at Fantasy Sports Require Skill or Dumb Luck?, WIRED (Oct. 17, 2015), https://www.wired.com/2015/10/does-winning-at-fantasysports-require-skill-or-dumb-luck/; Shirley Leung, DraftKings and the Power of Luck, Boston GloBe (Oct. 21, 2015), https://www.bostonglobe.com/business/ 2015/10/20/fantasy-sports-game-chance-skill/zab5CLxnF5zRxkwRxCuEnI/story .html.

${ }^{10}$ Tenn. Att'y Gen. Op. No. 16-13 (Apr. 5, 2016); Tx. Att'y Gen. Op. No. KP-0057 (Jan. 19, 2016).

${ }^{11}$ Lucinda Shen, DraftKings and FanDuel Settle New York Lawsuit for \$12 Million, FORTUNE (Oct. 26, 2016), http://fortune.com/2016/10/26/draftkings-fanduelsettlement/.

${ }^{12}$ Ed Miller and Daniel Singer, For Daily Fantasy-Sports Operators, the Curse of Too Much Skill, McKinsey \& COMPANY (Sept. 2015), https://www.mckinsey.com/ game of skill or luck? ${ }^{9}$ Many concluded that daily fantasy must be a game of luck because of factors such as the ability of a player becoming injured or ejected, weather conditions, the state of game equipment, and more. ${ }^{10}$

On the other hand, some attorneys general also were concerned about the imbalance in prize winnings. The New York attorney general found that $89 \%$ of players lost money playing on the daily fantasy website DraftKings. ${ }^{11}$ A McKinsey study showed that a mere $1.3 \%$ of daily fantasy players were winning $91 \%$ of the all prize money. ${ }^{12}$ The other $98.7 \%$ of players were splitting the remaining $9 \%$ of winnings. ${ }^{13}$ From a consumer protection viewpoint, regulators were concerned that daily fantasy players were being taken advantage of by so-called sharks. ${ }^{14}$ In effect, the skill advantage was so great that regular players had no chance of winning. ${ }^{15}$

How can both views be accurate? If daily fantasy is a game of chance, the best players should not be able to win consistently. But the data showed that the top players were winning most of the prizes. ${ }^{16} \mathrm{~A}$ contextual analysis of skill and luck in daily fantasy demonstrates how this situation can emerge. If two players are vastly apart in skill, the variance in their skill will dwarf the presence of luck. As many new players flocked to the daily fantasy games, they played against expert players who had more data, more information, and more skill. The expert players reaped the rewards of their skill. However, if two players were of closer skill, the luck factors identified above, like player injury or weather, could determine the outcome of the contest. Skill matters in daily fantasy, and luck matters in daily fantasy. How much each matters depends on the context of the individual players, not on the nature of the game itself. industries/media-and-entertainment/our-insights/for-daily-fantasy-sports-operatorsthe-curse-of-too-much-skill.

${ }^{13} I d$.

${ }^{14}$ Jay Caspian King, How the Daily Fantasy Sports Industry Turns Fans into Suckers, N.Y. Times Magazine (Jan. 6, 2016), https://www.nytimes.com/2016/01/ 06/magazine/how-the-daily-fantasy-sports-industry-turns-fans-into-suckers.html.

${ }^{15}$ Some concerns were related to the potential insider trading by employees of daily fantasy companies. See Joe Drape and Jacqueline Williams, Scandal Erupts in Unregulated World of Fantasy Sports, N.Y. Times (Oct. 5, 2015), https://www .nytimes.com/2015/10/06/sports/fanduel-draftkings-fantasy-employees-bet-rivals html. However, the amount of disproportionate winnings outlined in Miller and Singer, supra note 12 , cannot be explained by employee players alone.

${ }^{16}$ Miller and Singer, supra note 12. 
The idea that there are two types of games, those of skill and those of luck, breaks down under careful analysis. All games will be determined by luck given the appropriate context. Some games can be determined as being all luck, but a game can never be wholly determined by skill in every situation. Con- text matters in determining the relative nature of games. Courts, legislatures, and regulators should expand their views beyond the expedient but false dichotomy that games are absolutely skill-based or luck-based. As this area of law develops, a richer understanding of luck and skill is required. 